Article

\title{
How Much Are Insurance Consumers Willing to Pay for Blockchain and Smart Contracts? A Contingent Valuation Study
}

\author{
Seung Oh Nam \\ Department of IT-Finance Management, Soonchunhyang University, 646 Eupnae-ri, Shinchang-myeon, \\ Asan-si 31538, Choongchungnam-do, Korea; sonam@sch.ac.kr; Tel.: +82-41-530-1688; Fax: +82-41-530-1787
}

Received: 29 September 2018; Accepted: 19 November 2018; Published: 21 November 2018

\begin{abstract}
Blockchain is highly secure in design and can hand huge data efficiently. A smart contract, based on a blockchain, can automate the entire process and make the contract self-executing in nature. Since the first introduction of these technologies in the 1990s, they have been at the center interest for academia and industry. Numerous researchers and practitioners have investigated the principles and usage of blockchain and smart contracts. However, little is coincidental regarding estimating the consumer's additional willingness to pay (WTP) and analyzing the relationship with socio-economic characteristics of the consumer for blockchain and smart contracts in the insurance sector. This study conducted the survey on 1000 heads of the household or homemakers who represent population well in South Korea and estimated additional WTP using one-and-one-half-bounded dichotomous choice contingent valuation (OOHB DC CV) method. About $65 \%$ of sample respondents answered they are willing to pay some additional premium for blockchain and smart contracts. The mean WTP has the value of KRW 28,425.43 (USD 25.38) and the median WTP is KRW 16,111.71 (USD 14.39). Those with high incomes, high education and more insurance contracts are more likely to pay extra for insurance policies using blockchain and smart contracts. Considering the total number of households in South Korea, the aggregated additional WTP is about 8 percent of the net income of the insurance industry in fiscal year of 2017. Consequently, strategic development of insurance products using block chains and smart contracts targeting educated consumers with high-income will increase the number of policyholders, which can in turn increase premium revenues.
\end{abstract}

Keywords: blockchain; smart contracts; willingness to pay; contingent valuation

\section{Introduction}

Some have documented that the blockchain is the greatest revolution since the internet. Indeed blockchain is receiving increasing attention from academia and industry. The South Korean government believes the country faces a global transformation called the Fourth Industrial Revolution and has announced blockchain, artificial intelligence, big data, cloud, virtual reality, augmented reality, autonomous vehicles, and drones as innovation growth industries [1].

A blockchain is a chain of previously validated blocks of transactions that constitute an immutable distributed, decentralized digital ledger that, when combined with a digital transaction validation process, allows for peer-to-peer electronic transfer of an asset without the need for an intermediary [2].

Smart contracts generally recorded onto a blockchain and validated by the network are computer programs, the correct execution of which is automatically enforced by underlying legal agreement without relying on a trusted authority [3].

In the banking industry, blockchain has been used to transfer money between parties without having to rely on banks through simplifying the business process while creating safe, trustworthy 
records of agreement and transactions [4]. As the insurance industry lagged behind banking because of their conservative attribute, just started to invest to explore the possibilities of blockchain and smart contracts for their business [5]. Consultancy firms investigated applicability of these technologies on the insurance domain and anticipated that blockchain and smart contracts enable to improve customer engagement by providing a greater degree of transparency and to the perceived fairness of claims handling. They also expected to enable blockchain and smart contracts to offer cost-efficient production for emerging markets and develop insurance products related to the Internet of Things (IoT) [6-8]. For example, when accidents or crimes occur, claims written by the legal language are typically complex and difficult to understand are processed automatically using blockchain and smart contracts. Additionally, fraud related to the integrity of a policy or claim will be reduced by sharing all transactions written to it and will minimize counterfeiting, double booking, document or contract alterations [9].

The blockchain based system, aiming to realize an automated, real-time, and immutable feedback loop between the insurance company, its customer, third parties and potential auditors, was proposed for one of the emerging market, cyber insurance that deals with an insurance product used to protect businesses and individual users from internet-based risks [10]. Also, there are studies providing insurance products combining blockchain and smart contracts with other technologies such as IoT, artificial intelligence (AI). On-demand car insurance system using smart contracts and IoT that increases the significance with the amount of data is introduced for decreasing policy modification costs [11]. While blockchain can assure safety and reliability, adding AI capabilities can greatly benefit the healthcare insurance sector. Presently, AI is mainly used for detecting abnormalities in X-rays and CT scans, a task performed at least as accurately and quickly as humans can, and assuring a great level of cost and time reduction about the healthcare insurance claim processing [12]. Several companies have launched a blockchain based system or insurance for securing documents and customer satisfaction [13, 14]. Similarly, blockchain and smart contracts are expected to offer benefits to both insurance companies and policyholders, but the focus of this study is consumer benefits. This is because the insurance premium, the main source of income for an insurance company, should be determined by the benefit of the policyholder rather than by the cost of the insurance company. Indeed an improvement in the function or quality of a product is of no use unless the consumer recognizes its value and reflects it in their decision to purchase the product [15].

On the other hand, it is true that there are concerns that the hype cycle for the insurance sector shows blockchain and smart contract at the beginning stage of the curve, which means this technology has not been fully explored yet [16]. It will cost much money to invest in blockchain and smart contracts, but the Korean insurance companies must decide seriously whether make the number of investments now to be in a position to take advantage of efficiencies and opportunities can deliver long-term business sustainability. They faced the issue of measuring the benefit of the consumer about these technologies. Many researchers use the principles of WTP that is the maximum amount of money a consumer is willing to spend for a product or service to measure the value [16-19]. This is based on the individual theory of consumer behavior (i.e. consumers are able to evaluate the utility of benefit from technologies in monetary units) [17].

The purpose of this study is to help insurance companies make a decision on investing in a new business ecosystem and an adjustment to the insurance premium by providing information about the consumers' WTP for blockchain and smart contracts in South Korea. Knowing consumers' WTP, companies can estimate the incremental revenue from insurance premium and pursue a pricing strategy suitably customized to their marketing environment and see valuable sources for increasing the profitability of the product offered [18]. As mentioned above, many researchers and practitioners have explored blockchain and smart contracts in the insurance sector, but have not studied on additional WTP, realistic values felt by consumers. In addition, this study provides the effect on WTP by the characteristics of a consumer as covariates. 
The remainder of this study is organized in the following fashion. In Section 2, the description of the research design is given. This consists of research target and sampling, survey format and survey instrument. Section 3 explains the methodology used in this study and explores data from the survey. Section 4 provides results and discussions considered by insurance companies. Conclusions are presented in Section 5 .

\section{Research Design}

\subsection{Research Target and Sampling}

According to Korean Statistical Information Service (KSIS), the number of contracts of insurance reached 3 billion for life insurance alone as of August 2018. As most policyholders have difficulties from difficulty in insurance claims processing, they may pay additional premiums if insurance claims are simplified. To measure additional annual insurance premiums as a payment vehicle per household, this study conducted a survey on heads of the household or homemakers who are selected as a stratified sampling design based on the socio-economic statistics in South Korea. Professional survey company conducted the entire process of sampling and survey. To make sure that sample characteristics represent the population characteristics, the ratio of age, sex, region and so on were predetermined in accordance with the statistics of KSIS and experts sampled from the company's database.

\subsection{Survey Format}

This study estimated insurance consumers' additional WTP for blockchain and smart contracts using contingent valuation (CV) method which is standardized and most popular approach [19-22]. Initially, the CV method was designed to measure the value of non-market resources, such as environmental preservation or public goods under the assumption of a hypothetical situation. As the reliability and validity of the methodology have been verified, the scope of application is expanded to goods that are difficult to measure for utility.

This study used the dichotomous choice (DC) method that is one of the guidelines recommended by NOAA-panel [23] for implementing the CV method. In the DC method, respondents are asked whether they would be willing to pay for a given sum of money and answer "yes" or "no" simply. Haneman et al. [24] introduced the double-bounded (DB) DC method which requires two prices because the single-bounded (SB) DC method has a low statistical efficiency problem. Cooper et al. [25], however, provided a one-and-one-half-bounded (OOHB) DC method in order to reduce the response bias caused by DB DC method. In OOHB DC CV surveys, one current and the other hypothetical situation, where blockchain and smart contracts are implemented, are first explained to the respondents. After explanations, respondents are given the first SB DC CV style question in the first step, and then only respondents who meet specific conditions are given an additional SB DC CV style question in the second step. Following Cooper et al., OOHB DC CV survey was conducted in this study.

\subsection{Survey Instrument}

In order to build up the survey instrument, including a list of bid prices, the revised and adapted survey instrument was then tested in a small focus group of 36 people in January 2018. This ensured interpretation or comprehension of the information provided on the survey instruments. Final survey form made by this process included three sections. The first section, which is standard for all studies, contained the purpose of the survey and a brief guidance. Additionally, there existed details and a sufficient explanation about the benefits of blockchain and smart contracts in the insurance sector. In the second section, there were the principal valuation questions that aimed to evaluate the WTP. Finally, the third section collected demographic and socio-economic information of the individuals. The main valuation question is as follow. Considering your household expenditures, are you willing to additionally pay (a bid amount) money (insurance premium per year) from your household income for insurance claim process improvement by blockchain and smart contracts so that the insurance company 
could implement this technology? With this survey instruments, a professional survey company conducted in-person completed interviews that is the most controllable and effective means [26,27] between March and June 2018 on a national scale in South Korea.

\section{Methodology and Data}

\subsection{Empirical Model}

This study used OOHB DC CV method known as Cooper et al.'s approach. A list of bid ranges, $B_{j}^{L}$ and $B_{j}^{H}(j=1,2, \ldots, J)$, where $B_{j}^{L}<B_{j}^{H}$, is decided. According to the number of $J$, all respondents are divided into $J$ groups which have a similar number of respondents. Only one of the bid ranges $\left(B_{j}\right)$ is selected at random and one $\left(B_{j}^{L}\right.$ or $\left.B_{j}^{H}\right)$ of these two bid prices is presented randomly to about the half of respondents in $j$ group. The other $\left(B_{j}^{H}\right.$ or $\left.B_{j}^{L}\right)$ of these two bid prices are presented at random to the other half of respondents in the same $j$ group.

For example, if the half of respondents in a group are asked whether they would be willing to pay the amount of the bid $\left(B_{j}^{L}\right)$ and the answer is "yes", then they are asked additionally whether they would be willing to pay the amount of the bid $\left(B_{j}^{H}\right)$. If the response is "no", then there is no additional question. And then the other half of respondents in the same group are asked about the amount of the bid $\left(B_{j}^{H}\right)$. If their answer is "no", then they are also asked additionally whether they would be willing to pay the amount of the bid $\left(B_{j}^{L}\right)$. Consequently, there are six possible responses to the OOHB DC CV survey: "no", "yes-no", and "yes-yes" when the lower bid is shown in the first and "yes", "no-yes", and "no-no" when the higher bid is shown in the first. Let $d_{i}^{*}(i=1,2, \ldots, N)=1$ if $i$ th respondents answer "*", and 0 otherwise. Of course, * represents above six responses.

$$
\begin{gathered}
d_{i}^{N}=1 \text { (the response of } i \text { respondent is "no") } \\
\left.d_{i}^{Y N}=1 \text { (the response of } i \text { respondent is "yes }- \text { no"}^{\prime}\right) \\
d_{i}^{Y Y}=1 \text { (the response of } i \text { respondent is "yes }- \text { yes") } \\
d_{i}^{Y}=1 \text { (the response of } i \text { respondent is "yes") } \\
d_{i}^{N Y}=1 \text { (the response of } i \text { respondent is "no }- \text { yes") } \\
d_{i}^{N N}=1 \text { (the response of } i \text { respondent is "no }- \text { no") }^{N N}
\end{gathered}
$$

As shown by Hanemann [28], corresponding probabilities for six responses are denoted by $\pi_{i}^{N}, \pi_{i}^{Y N}, \pi_{i}^{Y Y}, \pi_{i}^{Y}, \pi_{i}^{N Y}$, and $\pi_{i}^{N N}$ :

$$
\begin{gathered}
\pi_{i}^{N}=\operatorname{Pr}\left(C_{i} \leq B_{i}^{L}\right)=G\left(B_{i}^{L} ; \theta\right) \\
\pi_{i}^{Y N}=\operatorname{Pr}\left(B_{i}^{L} \leq C_{i} \leq B_{i}^{H}\right)=G\left(B_{i}^{H} ; \theta\right)-G\left(B_{i}^{L} ; \theta\right) \\
\pi_{i}^{Y Y}=\operatorname{Pr}\left(B_{i}^{H} \leq C_{i}\right)=1-G\left(B_{i}^{H} ; \theta\right) \\
\pi_{i}^{Y}=\operatorname{Pr}\left(B_{i}^{H} \leq C_{i}\right)=1-G\left(B_{i}^{H} ; \theta\right) \\
\pi_{i}^{N Y}=\operatorname{Pr}\left(B_{i}^{L} \leq C_{i} \leq B_{i}^{H}\right)=G\left(B_{i}^{H} ; \theta\right)-G\left(B_{i}^{L} ; \theta\right) \\
\pi_{i}^{N N}=\operatorname{Pr}\left(C_{i} \leq B_{i}^{L}\right)=G\left(B_{i}^{L} ; \theta\right)
\end{gathered}
$$

where $G(B ; \theta)$ denotes a cumulative distribution function of WTP and $C_{i}$ is the households' true maximum WTP for the blockchain and smart contracts in insurance that is the subject of the survey.

These can be compressed into three groups according to the probabilities as follows:

$$
\begin{gathered}
\pi_{i}^{N}=\pi_{i}^{N N}=\operatorname{Pr}\left(C_{i} \leq B_{i}^{L}\right)=G\left(B_{i}^{L} ; \theta\right) \\
\pi_{i}^{Y N}=\pi_{i}^{N Y}=\operatorname{Pr}\left(B_{i}^{L} \leq C_{i} \leq B_{i}^{H}\right)=G\left(B_{i}^{H} ; \theta\right)-G\left(B_{i}^{L} ; \theta\right) \\
\pi_{i}^{Y Y}=\pi_{i}^{Y}=\operatorname{Pr}\left(B_{i}^{H} \leq C_{i}\right)=1-G\left(B_{i}^{H} ; \theta\right)
\end{gathered}
$$


Following a logit model that is most widely used by researchers in studying WTP, $G(B ; \theta)$ is assumed as:

$$
G(B ; \alpha, \beta)=\frac{1}{1+\exp (\alpha-\beta \ln B)}
$$

where $\alpha$ and $\beta$ are the parameters.

Therefore, the $\log$-likelihood function $\operatorname{lnL}(\alpha, \beta)$ becomes:

$$
\begin{gathered}
\ln L(\alpha, \beta)=\sum_{i=1}^{N}\left\{d_{i}^{Y} \ln \left[1-G\left(B_{i}^{H} ; \alpha, \beta\right)\right]\right. \\
+d_{i}^{Y N} \ln \left[G\left(B_{i}^{H} ; \alpha, \beta\right)-G\left(B_{i}^{L} ; \alpha, \beta\right)\right] \\
\left.+d_{i}^{N} \ln \left[G\left(B_{i}^{L} ; \alpha, \beta\right)\right]\right\}
\end{gathered}
$$

The parameters $\alpha$ and $\beta$ can be estimated with maximization of the log-likelihood function.

\subsection{Data}

The dataset used in the analysis consists of 1000 responses obtained from CV survey. The households' characteristics of the sample are summarized in Table 1. The mean (median) of sample gross household income per year was KRW 62,283,800 $(60,000,000)$, the average education period was over 14 years, the average age of respondents was 45.58 years old, the ratio of gender was almost one to one, about $70 \%$ of the sample consisted of married people and the sample households held 3.04 insurance policies on average. This sample is similar to the population parameters, according to data released by KSIS 2017 Census. The average gross household income per year of the population was KRW 56,100,000 (USD 50,089), the average age of the population was 43 years old, the average

\begin{tabular}{|c|c|c|c|c|c|}
\hline Characteristics & Details & Frequency & Mean & Median & Standard Deviation \\
\hline \multirow{6}{*}{ Income (million KRW/year) } & $1-50$ & 427 & \multirow{6}{*}{62.28} & \multirow{6}{*}{60} & \multirow{6}{*}{33.37} \\
\hline & $51-100$ & 500 & & & \\
\hline & $101-150$ & 58 & & & \\
\hline & $151-200$ & 11 & & & \\
\hline & $201-250$ & 1 & & & \\
\hline & $251-300$ & 3 & & & \\
\hline \multirow{5}{*}{ Education (year) } & $6-9$ & 42 & \multirow{5}{*}{14.85} & \multirow{5}{*}{16} & \multirow{5}{*}{2.51} \\
\hline & $10-13$ & 248 & & & \\
\hline & $14-17$ & 607 & & & \\
\hline & $18-21$ & 86 & & & \\
\hline & $22-25$ & 17 & & & \\
\hline \multirow{6}{*}{ Age (year) } & $20 \mathrm{~s}$ & 200 & \multirow{6}{*}{45.58} & \multirow{6}{*}{46} & \multirow{6}{*}{14.24} \\
\hline & $30 \mathrm{~s}$ & 200 & & & \\
\hline & $40 \mathrm{~s}$ & 196 & & & \\
\hline & $50 \mathrm{~s}$ & 200 & & & \\
\hline & $60 s$ & 200 & & & \\
\hline & $70 \mathrm{~s}$ & 204 & & & \\
\hline \multirow[b]{2}{*}{ Gender } & Male & 507 & \multirow{2}{*}{-} & \multirow{2}{*}{-} & \multirow{2}{*}{-} \\
\hline & Female & 493 & & & \\
\hline \multirow{2}{*}{ Married } & Married & 695 & \multirow{2}{*}{-} & \multirow{2}{*}{-} & \multirow{2}{*}{-} \\
\hline & Single & 305 & & & \\
\hline
\end{tabular}
ratio female was about $50 \%$ and the average ratio of married people was $60 \%$ in 2017 . This means that the sample represents the population well.

Table 1. Descriptive Statistics. 
Table 1. Cont.

\begin{tabular}{cccccc}
\hline Characteristics & Details & Frequency & Mean & Median & Standard Deviation \\
\hline & 0 & 61 & & & \\
1 & 107 & & & \\
2 & 194 & & & \\
Contracts & 3 & 249 & & & \\
& 4 & 220 & 3.04 & 3 & \\
& 5 & 109 & & \\
& 6 & 48 & & \\
7 & 11 & & \\
& 7 & 1 & & \\
\hline
\end{tabular}

Notes: Income refers to gross household income before tax in 2017. Education refers to the period of education from elementary school. Age refers to the respondent's age. Gender refers to the respondent's sex. Married refers to marital status. Contracts are the total number of insurance contracts held by a household.

The bid ranges (in Korean Won; KRW, 1 USD $=1120 \mathrm{KRW}$ ) used in valuation question were (3000, $10,000),(8000,15,000),(13,000,20,000),(18,000,25,000),(23,000,30,000)$, and $(28,000,33,000)$. According to the number of bid ranges, 1000 respondents were divided into six groups. Each group had almost same sample size (164 168 respondents).

Table 2 shows the bid values of each bid range and response summaries. 187, 167, 140 people responded "no", "yes-no", and "yes-yes" respectively out of the 494 people who are offered lower bound bid first and 162, 175, 169 people responded respectively "yes", "no-yes", and "no-no" out of the 506 people who are offered upper bound bid first. One important result of this analysis is the fact that over $64 \%$ out of 1000 respondents said they were willing to pay either the first or the second bid amount.

Table 2. Responses for Bid Ranges.

\begin{tabular}{|c|c|c|c|c|c|c|c|c|}
\hline \multirow{3}{*}{\multicolumn{2}{|c|}{ Bid Ranges ${ }^{a}\left(B_{j}^{L}, B_{j}^{H}\right)$}} & \multicolumn{6}{|c|}{ Responses $^{\mathbf{b}}$} & \multirow{3}{*}{ Sample Size } \\
\hline & & \multicolumn{3}{|c|}{$\begin{array}{c}\text { Lower Bound Bid }\left(B_{j}^{L}\right) \\
\text { Offered First }\end{array}$} & \multicolumn{3}{|c|}{$\begin{array}{l}\text { Upper Bound Bid }\left(B_{j}^{L}\right) \\
\text { Offered First }\end{array}$} & \\
\hline & & $\mathbf{N}$ & YN & $Y Y$ & $\mathbf{Y}$ & NY & NN & \\
\hline 3000 & 10,000 & 20 & 23 & 37 & 41 & 27 & 16 & 164 \\
\hline 8000 & 15,000 & 32 & 30 & 23 & 32 & 29 & 22 & 168 \\
\hline 13,000 & 20,000 & 28 & 33 & 22 & 34 & 29 & 22 & 168 \\
\hline 18,000 & 25,000 & 26 & 30 & 27 & 20 & 34 & 30 & 167 \\
\hline 23,000 & 30,000 & 40 & 26 & 16 & 22 & 27 & 36 & 167 \\
\hline 28,000 & 35,000 & 41 & 25 & 15 & 13 & 29 & 43 & 166 \\
\hline \multicolumn{2}{|c|}{ Totals } & 187 & 167 & 140 & 162 & 175 & 169 & 1000 \\
\hline
\end{tabular}

Notes: ${ }^{a}$ Unit of bid ranges is KRW (1 USD $\left.=1120 \mathrm{KRW}\right) .{ }^{\mathrm{b}} \mathrm{N}, \mathrm{YN}, \mathrm{YY}, \mathrm{Y}, \mathrm{NY}$, and NN refer the number of respondents who answered "no", "yes-no", "yes-yes", "yes", "no-yes", and "no-no" respectively.

\section{Results}

\subsection{Estimation Results without Covariate}

This model is often called the restricted or null model, meaning that none of the excluded covariates affects the choice behavior of WTP. Estimation results were obtained with using maximum likelihood estimation (MLE) method that maximizes Equation (5) derived from Hanemann utility difference model. Table 3 shows the parameters $\alpha$ and $\beta$ estimation. The variable $\ln ($ bid) for the model is statistically significant at 0.000 level. In addition to the high level of significance, the coefficient has expected negative signs indicating a negative relationship with the dependent variable. In other words, the higher the additional insurance premium, the less likely the probability that the respondent would be willing to pay. 
Table 3. Estimation Results without Covariate.

\begin{tabular}{cccccc}
\hline Variable & Coefficient & Std. Error & $\mathbf{z}$ & $\operatorname{Pr}(>|\mathbf{z}|)$ & $\mathbf{9 5 \%}$ Confidence Interval \\
\hline Intercept & 17.50 & 0.79 & 22.14 & $0.000^{* * *}$ & $15.95,19.05$ \\
Ln(bid) & -1.81 & 0.08 & -22.41 & $0.000 * * *$ & $-1.97,-1.65$ \\
\hline
\end{tabular}

Notes: Log-likelihood is -1241.52 . The convergence is true. ${ }^{* * *}$ indicates statistical significance at the 0.000 level.

This study has assumed that WTP is a non-negative random variable and the mean WTP was calculated using methods proposed by Hanemann (1989) and Hanemann et al. (1991).

$$
\mathrm{E}(\mathrm{WTP})=\mathrm{WPT}_{\text {mean }}=\int_{0}^{\infty}(1-G(B ; \alpha, \beta)) d B=\exp \left(\frac{-\alpha}{\beta}\right) \frac{\frac{\pi}{\beta}}{\sin \left(\frac{\pi}{\beta}\right)}
$$

The mean WTP has the value of KRW 28,425.43 (USD 25.38) (mean truncated at the maximum bid: 18,448.01 (USD 16.47), adjusted mean truncated at the maximum bid with adjustment: 22,991.97 (USD 20.53) and the median WTP is KRW 16,111.71 (USD 14.39). Table 4 shows the point estimation and their confidence intervals for location measurement of WTP using the method of Krinsky and Robb [29,30].

Table 4. Willingness to pay (WTP) Confidence Intervals.

\begin{tabular}{cccc}
\hline & \multirow{2}{*}{ Estimate (KRW) } & \multicolumn{2}{c}{$\mathbf{9 5 \%}$ Confidence Interval (KRW) } \\
\cline { 3 - 4 } & & Lower Bound & Upper Bound \\
\hline Mean & 28,425 & 25,257 & 32,497 \\
Truncated Mean & 18,448 & 17,685 & 19,199 \\
Adjusted Truncated Mean & 22,992 & 21,486 & 24,547 \\
Median & 16,115 & 15,074 & 17,204 \\
\hline
\end{tabular}

Notes: The confidence intervals are simulated by the Krinsky and Robb method.

\subsection{Estimation Results with Covariate}

In this section, a model containing covariates was estimated to analyze how the characteristics of respondents or households affected the possibility of paying additional insurance premiums. As mentioned above, six variables (income, education, age, gender, married, contracts) were considered as covariates. Table 5 provides the results of model estimation. The overall model is statistically significant, LR statistic that calculated under the null hypothesis of all parameters jointly zero is high enough. The coefficient estimates for $\ln$ (bid), $\ln$ (income), education, and contracts are statistically meaningful at the level of 0.000 and the estimate for gender is statistically meaningful at the 0.01 level. Age and marital status, however, does not affect additional willingness to pay behavior. The income, education level, and the number of holding insurance policies are positively related to the probability that the respondent would be willing to pay.

Table 5. Estimation Results with Covariate.

\begin{tabular}{cccccc}
\hline Variable & Coefficient & Std. Error & $\mathbf{z}$ & $\operatorname{Pr}(>|\mathbf{z}|)$ & $\mathbf{9 5 \%}$ Confidence Interval \\
\hline Intercept & -3.0127 & 4.60 & -0.65 & 0.51 & $-12.03,6.00$ \\
Ln(bid) & -2.4488 & 0.11 & -22.50 & $0.000^{* * *}$ & $-2.66,-2.23$ \\
Ln(Income) & 1.0742 & 0.26 & 4.10 & $0.000^{* * *}$ & $0.56,1.58$ \\
Education & 0.3214 & 0.04 & 7.17 & $0.000^{* * *}$ & $0.24,0.40$ \\
Age & 0.0078 & 0.01 & 1.25 & 0.21 & $-0.01,0.03$ \\
Gender & 0.3536 & 0.14 & 2.44 & $0.01^{*}$ & $0.08,0.63$ \\
Married & -0.2194 & 0.17 & -1.27 & 0.20 & $-0.55,0.11$ \\
Contracts & 0.7206 & 0.08 & 8.57 & $0.000^{* * *}$ & $0.56,0.88$ \\
\hline
\end{tabular}

Notes: Log-likelihood is -948.36 . LR statistics is 586.32 ( $p$-value: 0.000$)$. The convergence is true. ${ }^{*}$ indicates statistical significance at the 0.01 level. ${ }^{* * *}$ indicates statistical significance at the 0.000 level. 
The mean WTP calculated by (7) has the value of KRW 19,170.32 (USD 17.12) and the median WTP is KRW 14,327.80 (USD 12.79).

$$
\mathrm{E}(\mathrm{WTP})=\mathrm{WPT}_{\text {mean }}=\int_{0}^{\infty}(1-G(B ; \alpha, \beta)) d B=\exp \left(\frac{-\alpha^{*}}{\beta}\right) \frac{\frac{\pi}{\beta}}{\sin \left(\frac{\pi}{\beta}\right)}
$$

where $\alpha^{*}$ is the adjusted intercept by summing the coefficient of all variables, except $\ln (\mathrm{bid})$.

Table 6 shows the point estimation and their confidence intervals for location measurement of WTP.

Table 6. WTP Confidence Intervals.

\begin{tabular}{|c|c|c|c|}
\hline & \multirow{2}{*}{ Estimate (KRW) } & \multicolumn{2}{|c|}{ 95\% Confidence Interval (KRW) } \\
\hline & & Lower Bound & Upper Bound \\
\hline Mean & 19,170 & 17,872 & 21,004 \\
\hline Truncated Mean & 16,565 & 15,812 & 17,379 \\
\hline Adjusted Truncated Mean & 18,424 & 17,342 & 19,792 \\
\hline Median & 14,328 & 13,531 & 15,228 \\
\hline
\end{tabular}

Notes: The confidence intervals are simulated by the Krinsky and Robb method.

\subsection{Insurance Company Policy Implications}

Above estimate results help insurance companies determine the profitability of investing in blockchain and smart contracts in South Korea. KSIS announced the total households are about 20 million in 2017 Census. If we use the median WTP excluded covariate effects on the conservative side, the total amount of additional insurance consumers' WTP is about KRW 322 billion (USD 288 million) for benefit of newer technologies. The 95\% confidence interval for it is KRW 301 billion (USD 269 million) and KRW 344 billion (USD 307 million). This is $0.16 \sim 0.18 \%$ of the total insurance premium for 2017 (KRW 191 trillion, USD 171 billion), and 7.77 8.87\% of the total insurance companies' net income for 2017 (KRW 3878 billion, USD 3463 million) announced by Financial Supervisory Service. Of course, when calculating the increase in the total insurance companies' net income, an increment in the revenue and cost of an insurance company from investing in blockchain and smart contracts should be considered together; however, it was limited to the insurance premium domain and estimated. In addition, the implementation of blockchain and smart contracts will improve insurance claims processing and drive customer satisfaction. According to Korea Insurance Development Institute (KIDI), the total assets of the insurance industry have increased ten times and the revenues of insurance premiums three times over the past 20 years. Since it is difficult to expect high growth to continue in the future due to low birth rates and low rate of return, insurance companies need to change their management paradigms to find the next growth engine such as blockchain and smart contracts.

\section{Conclusions}

Since the concept of blockchain and smart contracts based on blockchain was first introduced in the 1990s, they have been at the center of great interest in academia and industry.

Blockchain technology can be highly secured by design and efficient for huge data. So, insurance companies processing entirely data-driven work have explored the power of blockchain technology. The smart contracts enable entire process to be automated and the contracts to be self-executing in nature. Thus for an insurance company and policyholder, it becomes very important to use it.

Some people addressed that blockchain and smart contracts have not been fully explored yet in the insurance sector but consultancy firms anticipated they will improve customer engagement, reduce cost, and development new insurance productions. Indeed French major insurance company AXA launched a new flight-delay insurance product using smart contracts in 2018. Under these 
circumstances, Korean insurance companies are wondering whether to invest in these technologies for their business sustainability.

The focus of this study is to help Korean insurance company make decisions on investment in blockchain and smart contracts and adjust premiums with consumers' additional WTP. It is meaningful that the utility of technology is considered as the determinants of premiums compared to current studies that considered demographic and socioeconomic variables. About $65 \%$ of the sample respondents are willing to pay some additional premium for blockchain and smart contract. This means that two out of three people are positive about insurance contracts using this technology than the premium they currently paid for and indicates the need to expand the insurance products using blockchain and smart contacts.

This study conducted the survey on 1000 heads of the household or homemaker that represents population well in South Korea and estimated insurance consumers' additional WTP for blockchain and smart contracts using OOHB DC CV method. As expected the higher the additional insurance premium, the less likely the probability that the respondent would be willing to pay. The median WTP excluded covariates effect has the value of KRW 16,111.71 (USD 14.39) per year for household holding entire insurance policies. This can be a useful baseline for insurance companies to raise premiums and prevent negative public opinion about the high rate of premiums and an estimate of incremental income from the insurance premium. Considering the total number of households in South Korea, the aggregated additional WTP is about 8 percent of the net income of the insurance industry in fiscal year 2017.

The findings from a model containing covariates also useful to design an insurance product by the characteristics of the consumer. The insurance premium is determined based on risk when designing an insurance product. In this case, although the insurance premium is different by measuring the risk arising from the characteristics of the consumer, the preference by characteristics for the insurance product is not considered. Using the results of this study, an insurance company can determine the superior customer of insurance product in advance by referring to changes in WTP according to the characteristics of the consumer and thus enable the classification strategy of products. People with high-income, high education, and more insurance contracts were more likely to pay extra for insurance policies using blockchain and smart contacts. The strategic development of insurance product targeting high-income and educated consumers will increase the number of policyholders, which in turn can increase insurance premium revenues.

What was regrettable during the study was that some informative data were not available, so this study were not able to estimate the additional WTP by insurance types, subscription period, and the amount of premium, and additional WTP for the people who cancel an insurance policy before end of the agreed term.

Acknowledgments: This work was supported by the Soonchunhyang University Research Fund.

Conflicts of Interest: The author declares no conflicts of interest

\section{References}

1. The Korea Herald. Korea Steps up to Spur 4th Industrial Revolution. Available online: http://www. theinvestor.co.kr/view.php?ud=20180124000332 (accessed on 2 September 2018).

2. Marr, B. A Complete Beginner's Guide to Blockchain. Available online: http://www.forbes.com/ sites/bernardmarr/2017/01/24/a-complete-beginners-guide-toblockchain/\#36e42ce666a6 (accessed on 2 September 2018).

3. Szabo, N. Formalizing and Securing Relationships on Public Networks. Available online: http:/ / ojphi.org/ ojs/index.php/fm/article/view/548/469 (accessed on 2 September 2018).

4. Treleaven, P.; Brown, R.G.; Yang, D. Blockchain technology in finance. Computer 2017, 50, 14-17. [CrossRef]

5. Lamberti, F.; Gatteschi, V.; Demartini, C.; Pranteda, C.; Santamaria, V. Blockchain or not blockchain, that is the question of the insurance and other sectors. IT Prof. 2017. [CrossRef] 
6. Kemp, L. Blockchain Applications in Insurance; Deloitte LLP: London, UK, 2016; pp. 1-2.

7. Lorenz, J.T.; Münstermann, B.; Higginson, M.; Olesen, P.B.; Bohlken, N.; Ricciardi, V. Blockchain in Insurance-Opportunity or Threat? McKinsey \& Company: New York, NY, USA, 2016; pp. 1-9.

8. Ernst \& Young. Blockchain in Insurance; Ernst \& Young LLP: London, UK, 2017; pp. 1-6.

9. Nath, I. Data Exchange Platform to Fight Insurance Fraud on Blockchain. In Proceedings of the 2016 IEEE 16th International Conference on Data Mining Workshops, Barcelona, Spain, 12-15 December 2016.

10. Ciocarlie, G.; Eldefrawy, K.; Lepoint, T. BlockCIS-A Blockchain-Based Cyber Insurance System. In Proceedings of the 2018 IEEE International Conference on Cloud Engineering (IC2E), Orlando, FL, USA, 17-20 April 2018.

11. Lamberti, F.; Gatteschi, V.; Demartini, C.; Pelissier, M.; Gomez, A.; Santamaria, V. Blockchains can cork for car insurance: Using smart contracts and sensors to provide on-demand coverage. IEEE Consum. Electron. Mag. 2018, 7, 72-81. [CrossRef]

12. Makridakis, S.; Polemitis, A.; Giaglis, G.; Louca, S. Blockchain: The Next Breakthrough in the Rapid Progress of AI. Available online: https:/ / www.intechopen.com/books/artificial-intelligence-emerging-trends-andapplications/blockchain-the-next-breakthrough-in-the-rapid-progress-of-ai (accessed on 5 October 2018).

13. Souter, G. Blockchain-Based Insurance Certificate Service Launched. Available online: https: / / www.businessinsurance.com/article/20181002/NEWS06/912324362/Blockchain-based-insurancecertificate-service-CertVault-launched-Patra-Corp (accessed on 8 October 2018).

14. Dawson, C. Axa Launches Blockchain Based Flight Delay Insurance Product Fizzy. Available online: https: / / www.cointrust.com/news/axa-launches-blockchain-based-flight-delay-insurance-product-fizzy (accessed on 8 October 2018).

15. Park, B.J. Pricing as Corporate Competitive Strategy, Shinhan FSB Review; Shinhan FSB Institute: Seoul, Korea, 2007. (In Korean)

16. Gatteschi, V.; Lamberti, F.; Demartini, C.; Pranteda, C.; Santamaria, V. Blockchain and smart contracts for insurance: Is the technology mature enough? Future Internet 2018, 10, 20. [CrossRef]

17. Hájek, P.; Stejskal, J. Modeling public library value using the contingent valuation method: The case of the Municipa Library of Prague. J. Libr. Inf. Sci. 2014, 47, 43-55.

18. Breidert, C.; Hahsler, M.; Reutterer, T. A review of methods for measuring willingness-to-pay. Innov. Mark. 2006, 2, 8-32.

19. Cummings, R.G.; Brookshire, D.S.; Bishop, R.C.; Arrow, K.J. Valuing Environmental Goods: An Assessment of the Contingent Valuation Method; Cummings, R.G., Brookshire, D.S., Schulze, W.D., Eds.; Rowman and Allenheld: Totowa, NJ, USA, 1986.

20. Cameron, M.R.; Carson, R.T. Using Survey to Value Public Goods: The Contingent Valuation Method; RFF Press: Washington, DC, USA, 1987.

21. Wang, J.; Ge, J.; Ma, Y. Urban Chinese consumers' willingness to pay for pork with certified labels: A discrete choice experiment. Sustainability 2018, 10, 603. [CrossRef]

22. Lim, S.Y.; Kim, H.Y.; Yoo, S.H. Public willingness to pay for transforming Jogyesa Buddhist temple in Seoul, Korea into a cultural tourism resource. Sustainability 2016, 8, 900. [CrossRef]

23. Arrow, K.; Solow, R.; Portney, P.R.; Leamer, E.E.; Radner, R.; Schuman, H. Report of the NOAA panel on contingent valuation. Fed. Regist. 1993, 58, 4601-4614.

24. Hanemann, W.M.; Loomis, J.; Kanninen, B. Statistical efficiency of double-bound dichotomous choice contingent valuation. Am. J. Agric. Econ. 1991, 73, 1255-1263. [CrossRef]

25. Cooper, J.C.; Hanemann, W.M.; Signorello, G. One-and-one-half-bounded dichotomous choice contingent valuation. Rev. Econ. Stat. 2002, 84, 742-750. [CrossRef]

26. Gürlük, S. The estimation of ecosystem services' value in the region of Misi rural development project: Results from a contingent valuation survey. For. Policy Econ. 2006, 9, 209-218. [CrossRef]

27. Berrens, R.P.; Bohara, A.K.; Silva, C.L.; Brookshire, D.; McKee, M. Contingent values for New Mexico in stream flows: With tests of scope, group-size reminder and temporal reliability. J. Environ. Manag. 2000, 58, 73-90. [CrossRef]

28. Hanemann, W.M. Welfare evaluations in contingent valuation experiments with discrete fesponses. Am. J. Agric. Econ. 1984, 66, 332-341. [CrossRef] 
29. Krinsky, I.; Robb, A.L. On approximating the statistical properties of elasticities. Rev. Econ. Stat. 1986, 68, 715-719. [CrossRef]

30. Krinsky, I.; Robb, A.L. On approximating the statistical properties of elasticities: A correction. Rev. Econ. Stat. 1990, 72, 189-190. [CrossRef] 